\title{
BREAD CONSUMPTION HABITS IN THE GLUTEN FREE DIET
}

\author{
Tünde Csapóné Riskó ${ }^{1}$ - Ádám Péntek ${ }^{2}$ - Troy Wiwczaroski ${ }^{3}$ \\ ${ }^{1}$ University of Debrecen, Faculty of Economics and Business, Institute of Marketing and Commerce, 138 \\ Böszörményi Str, Debrecen, Hungary, 4032 E-mail: risko.tunde@econ.unideb.hu \\ ${ }^{2}$ University of Debrecen, Faculty of Economics and Business, Institute of Applied Informatics and Logistics, 138 \\ Böszörményi Str, Debrecen, Hungary, 4032 E-mail: pentek.adam@econ.unideb.hu \\ ${ }^{3}$ University of Debrecen, Faculty of Economics and Business, Institute of Business Communication and Professional \\ Language Studies, 138 Böszörményi Str, Debrecen, Hungary, 4032 E-mail: troy.wiwczaroski@econ.unideb.hu
}

\begin{abstract}
Gluten is a protein found in many grain products. Celiac disease is a genetic autoimmune disorder characterized by sensitivity to gluten. When a person with celiac disease consumes gluten, his/her immune system perceives the gluten to be a harmful substance and reacts negatively. The only treatment for individuals with celiac disease is lifelong adherence to a gluten-free diet. It is one of the most frequent and well defined of all lifelong diseases. In Hungary, 1-2 \% of the population is said to be affected, but only every 10th has been diagnosed. Bread is a basic and frequently consumed food made principally from wheat. Gluten is the main structure-forming protein in flour, and is responsible for the elastic characteristics of dough, and contributes to the crumb structure and appearance of many baked products. Gluten removal results in major problems for bakers. Currently many gluten-free products available on the market are of low quality, exhibiting poor mouth feel and flavour. People wishing to eat bread in the gluten-free diet basically have two options: buying or baking the bread for themselves. There are several gluten-free bread brands are available on the Hungarian market. The price, ingredients, texture, colour, softness of the available breads are different. There is a rather good choice in gluten-free flour mixtures on the Hungarian market, as well. The composition of these mixtures are also different. The aim of our empirical research was to investigate the gluten-free bread consumption habits of people following gluten-free diet. The research was carried out using Google forms in January 2017. Size of the sample is 196. The online form was shared in four closed gluten free Facebook groups in Hungary since they are really active in sharing information concerning gluten-free lifestyle and diet.

Summarizing, in this study we wish to examine how evolve the world pork meat production, trade and consumption, and to demonstrate the main consuming countries, highlighting the role of China, as it is the most populated country in the world with its 1.4 billion inhabitants.
\end{abstract}

Keywords: celiac disease, gluten-free diet, bread. (JEL Code: M31)

\section{INTRODUCTION}

Celiac disease is a chronic, autoimmune disorder which is the result of an immune system response to the ingestion of gluten in susceptible persons. (Gluten is a generalised term that describes the storage proteins found in the common cereal grains wheat, rye, barley and their derivatives.) This immune response to gluten damages the small intestine and leads to malabsorption of nutrients and related health issues. The most common activators are stress, trauma and viral infections. Roughly $10-20 \%$ of first-degree relatives of those with celiac disease have the condition triggered in their lifetime. This disease is permanent and damage to the small intestine occurs always when gluten is consumed, regardless of whether or not symptoms are present. Celiac disease affects about 1 in 100 individuals worldwide, or over 3 million people in the United States alone. Although most patients remain undiagnosed as a result of variation in the severity and range of symptoms that a patient experiences. As regards the U.S. approximately $80 \%$ of those with celiac disease are undiagnosed (I1, I8, PANAGIOTOU and KONTOGIANNI, 2017). There are variations in the rate of prevalence in the different countries. In Europe, the rate of prevalence is $1 \%$, but in Germany, this rate is only $0.2 \%$, while in Finland and Sweden, the rates are $2-3 \%$ (I2). "Serological studies have shown the prevalence of celiac disease to be approximately $1 \%$ in the UK, the current prevalence of diagnosed celiac disease varies between $0.05 \%$ and $0.27 \%$ (SANDERS et al., 2003, VAN HEEL and WEST, 2006 in NELSON et al., 2007:410)." In Hungary, 1-2 \% of the population is said to be affected, but only every $10^{\text {th }}$ has been diagnosed (I3). Some symptoms of gluten-related disorders such as celiac disease or non-celiac gluten sensitivity are more likely to appear in women than men in general (I5). Figure 1 shows the rates of celiac disease worldwide. 
Figure 1. A global map of celiac disease

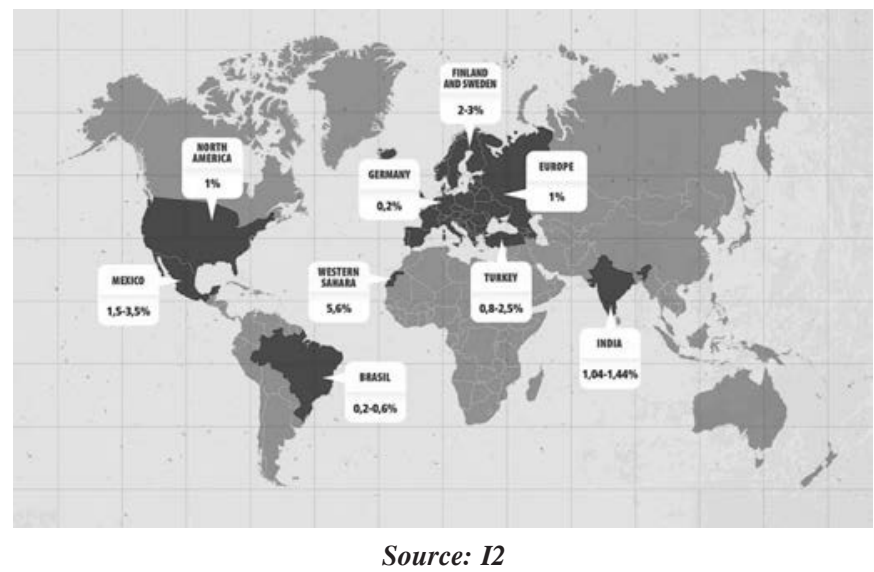

THE CELIAC DISEASE

A lifelong strict adherence to gluten-free diet is the only treatment currently available (SVERKER et al., 2007). Medicines usually are not required unless there is an accompanying condition, such as osteoporosis or dermatitis herpetiformis. It may take several months or longer for the small intestine to completely recover. Improvement can be measured by regular monitoring of the antibody blood tests used for screening, and by improved health. When one follows a gluten-free diet, blood tests should eventually come back to normal. It should be emphasised that this indicates good control of celiac disease and not a cure. Gluten-free diet is always required until another form of treatment is discovered (I1).

It has to be noted that celiac disease is now one of the most common gastrointestinal conditions in European populations and the clinical effectiveness of gluten-free diets in its treatment has been well documented (MAKI and COLLIN, 1997, MEARIN et al., 2005, HOLMES et al., 1989, VALDIMARSSON et al., 1996 in LOWDON, 2007).

One of the main problems individuals face in attempting to rearrange their lives is the lateness in which they are most often diagnosed with the disease. In the UK today, the average age of diagnosis for celiac disease is 45 years, with $25 \%$ of sufferers being diagnosed only after the age of sixty. Unlike in children, symptoms causing individuals to seek out a doctor for a diagnosis are often a trifle of what younger patients experience. Thus, diagnosis is not easy. More telling is, however, how difficult it is for older, yet newlydiagnosed patients to stick to their new dietary regimens (LOWDON, 2007). The risk of complications stemming from celiac disease are many and include links to osteoporosis and intestinal cancers. Therefore, the ability to manage one's diet may greatly impact both life expectancy and quality of life. In addition to the link to crippling conditions, such as osteoporosis and type 1 diabetes, there are dangers of combined diagnoses of unmanaged celiac disease and nondiagnosed lactose intolerance. (KEMPPAINEN et al., 1999, HOLMES et al., 1989 in NELSON et al., 2007). New patients, especially adults, must clearly recognize that their new, glutenfree diets represent lifelong obligations, should they want to continue to live productive lives into their golden years. For those who would avoid gluten without a clear diagnosis for their own supposedly health lifestyle choices, there is great danger in that avoidance leading to missed and false diagnoses, should digestive and metabolism-based symptoms appear later in life. Those who have been diagnosed and who do follow their new diets unfailingly they can enjoy long, symptom-free, healthy lives (I1).

\section{THE GLUTEN-FREE DIET}

On a gluten-free diet, wheat, rye and barley and any foods or ingredients derived from them must be removed from the diet. These food stuffs can include, for example, any form of bread product or bakery item, practically all noodletype foods, such as Italian pastas and lasagne pastas, as well as most other forms of bakery items containing gluten in their flour-based mixtures. As one source notes, some food stuffs available for purchase also contain gluten where many consumers least suspect them, such as in sauces for all kinds of ethnic foods, widely used salad dressings, packaged powder mixtures for and ready-made soups, as well as a wide range of popular processed foods (I4). Beverages are also on the list of gluten-containing items and these include practically all types of beer and malted beverages, although there are also further fermented drinks containing gluten in various forms (I8). Many consumers attempt to avoid gluten by purchasing oats, as this grain does not contain gluten. However, data shows that even oats are often sold in an already contaminated form, having come into contact with or been mixed with wheat during production and/or processing (I4). Thus, people with celiac disease must ensure that they possess a carefully prepared list of all those foods that they are allowed to eat and consistently, dutifully, follow it. In preparing such a list, four main categories may be used to somewhat simplify matters:

- foods that are naturally gluten-free

- natural gluten free grains and flours

- especially produced gluten-free products

- distilled vinegars and alcoholic beverages, as well as gluten-free certified wines and beers (Compare PANAGIOTOU and KONTOGIANNI, 2017, I8).

It is important to emphasise that gluten is often found in many food products that one would not expect, and glutencontaining ingredients can be found in almost any processed food product. Therefore, it is important to always check food labels. Consumers who are affected should make their purchases with caution and look for certified gluten-free products. Cross-contamination is a health threat to those suffering from celiac disease, and simply looking for such products as oat-containing foods instead of wheat-containing foods is dangerous. Cross-contamination is also a problem once food stuffs are brought into the home, and can occur whenever:

- foods are made on common surfaces

- with utensils that have been improperly cleaned after preparing gluten-containing foods

- difficult to clean equipment is utilized for both gluten- 
free and gluten containing foods

- common household food preparation appliances are used and improperly cleaned, including toasters, strainers and flour sifters. Celiac disease sufferers may have to purchase two sets of each appliance

- oil is used to deep-fry food and then reused for supposedly gluten-free food preparation

- spreadable condiments, including e.g. mustard, ketchup, mayonnaise, or margarine are applied with a knife to gluten-containing baked goods and then the knife is reinserted into a jar or container. The condiment becomes contaminated (I8).

Indeed, cross-contact contamination in the kitchen is preventable, but only with careful preparation and care. Those suffering from gluten-triggered illnesses may have to arrange their homes by physically separating items, and owning duplicate sets of utensils, tableware, cookware and any number of food preparation and serving paraphernalia. Additionally, the actual physical cleaning and cleansing of spaces and rooms used to prepare and serve meals has to be reorganized to ensure almost hospital operating room thoroughness in eliminating gluten in all its contaminant forms from air, surfaces and utilized items (I6).

\section{CONVENTIONAL BREAD IN HUMAN NUTRITION}

A true foundation of the human diet, bread has been present as an indispensable part of human meals for thirty thousand years. Bread provides us with vital energy, nutrients and other ingredients essential for good health, digestion and metabolism. As some one-half of the average individual's daily energy should be provided in the form of carbohydrates (including starch), bread is a necessary part of daily food intake (I9). Medical and nutritional research emphasize the importance of bread and other baked foods for nourishment (I10). While the consumption of white bread has decreased in the last 20 years on the Hungarian bakery market, it is still among the 5 most frequently consumed foods. Crescent rolls and other types of rolls are also frequently consumed, since they are among the 10 most frequently consumed foods in Hungary. $3 / 4$ of the population over 15 years consumes white bread several days per week, $58 \%$ on a daily basis. The average consumption of bread was $50 \mathrm{~kg}$, crescents $60 \mathrm{pcs}$, rolls 150 pcs per year per capita in 2010 in Hungary. Bread was purchased 67 times in a year, which comes to purchase every 5th day by Hungarian households (I7).

\section{GLUTEN-FREE BREADS}

Research shows that, unfortunately, many of the glutenfree bread products obtainable in shops and supermarkets are of poor quality and taste. Other complaints include reports of their dry, crumbling texture, which are unpleasing for consumers used to fresh, moist baked goods (YLIMAKI et al., 1991; ARENDT et al., 2002; GALLAGHER et al., 2003). FRIIS (1996) reports on the difficulties in completely removing all traces of allergenic protein from bread components in production. Research proves that residual gliadin can actually aggravate celiac disease and cause symptoms to continue in sufferers (CICLITIRA et al., 1985; THOMPSON 2001; SANCHEZ et al., 2002). GUJRAL et al. (2003) report that while rice flour enjoys hypoallergenic properties, its low protein content and inability to be used properly in kneading make bread preparation using rice flour a continuing challenge (Compare also KADAN et al., 2001 and McCARTHY et al., 2005).

Therefore, finding substitutes for gluten, at least in the bakery sector, represents a formidable technological problem. Gluten, good or bad, remains a necessary protein for baking bread with an agreeable, tasty structure that consumers want when making their baked goods purchases. Without gluten, dough loses its elasticity and becomes difficult to form. This is why gluten-free baked goods look like they do and are not moist, but crumby in consistency. Thus, many glutenfree products for sale today are still of comparably low quality, unpalatable and undesired (ARENDT et al., 2002). Overcoming these shortcomings will take a great deal of research and development. Although such activities have been ongoing for years, satisfactory substitutes are commonly not present on store shelves (Compare GALLAGHER et al., 2004).

Table 1. Gluten-free flours and their role in gluten-free bakery products

\begin{tabular}{|l|l|}
\hline Name of flour & Why and how to use it? \\
\hline Sorghum flour & $\begin{array}{l}\text { gluten free baking staple; adds protein with a } \\
\text { mild taste }\end{array}$ \\
\hline $\begin{array}{l}\text { White rice flour/brown } \\
\text { rice flour }\end{array}$ & $\begin{array}{l}\text { either one is great in a gluten free baking mix } \\
\text { recipe }\end{array}$ \\
\hline Sweet rice flour & great for breads and pizzas \\
\hline Tapioca starch/flour & $\begin{array}{l}\text { a thickener; also works well in combination } \\
\text { with other flours }\end{array}$ \\
\hline Potato starch & $\begin{array}{l}\text { a thickener for gravy; adds moisture to baked } \\
\text { goods }\end{array}$ \\
\hline Arrowroot starch & one of the most neutral thickeners for gravy \\
\hline Teff flour & great for desserts, has a slightly sweet flavor \\
\hline Buckwheat flour & great for waffles and pancakes \\
\hline Quinoa flour & $\begin{array}{l}\text { a great source of protein in baked goods; has } \\
\text { nice nutty taste }\end{array}$ \\
\hline Certified oat flour & $\begin{array}{l}\text { it has to be certified gluten-free; good in } \\
\text { breads }\end{array}$ \\
\hline Coconut flour & $\begin{array}{l}\text { great for desserts; coconut pairs well with } \\
\text { anything sweet }\end{array}$ \\
\hline Almond meal & $\begin{array}{l}\text { great for desserts, makes delicious crusts for } \\
\text { pies }\end{array}$ \\
\hline Hazelnut meal & great for special desserts \\
\hline
\end{tabular}

Source: based on 111

People wishing to eat bread in the gluten free diet basically have two options: buying or baking the bread for themselves. There are several gluten-free bread brands available on the Hungarian market. Ingredients, texture, colour, softness of these breads are different. There is a good choice in glutenfree flour mixtures on the Hungarian market, as well. The composition of these mixtures are also different. Table 1 shows some gluten-free flours and their role in gluten-free bakery products. 


\section{MATERIALS AND METHODS}

Bread is a basic and frequently consumed food made principally from wheat. Bread (gluten-free of course) is consumed by people with celiac disease, as well. The aim of our empirical research was to investigate the gluten-free bread consumption habits of people with celiac disease. Since there is rather good choice of gluten-free breads and glutenfree bread flour mixtures are available on the Hungarian market, we wanted to investigate how often and to which main meals the respondents eat bread and whether they buy or bake the bread for themselves. In both cases (buying baking) we investigated the motivations, frequencies and preferred brands, as well. A Web based survey was carried out in January 2017 in Hungary. The online questionnaire was shared in four closed gluten-free Facebook groups since they are really active in sharing information concerning gluten free lifestyle and diet. Size of the sample is 196. In the questionnaire the following question types were applied: dichotomous questions, multiple choice questions, rating scale questions, and demographic questions.

Almost $89.7 \%$ of the respondents is female and $10.3 \%$ male. $24.4 \%$ lives in the capital of Hungary (Budapest), $20.5 \%$ in county centres, $25.6 \%$ in other towns and $29.5 \%$ in other settlement types. There are seven NUTS 2 regions of Hungary, our respondents are representing all the NUTS 2 regions. By level of education half of the respondents (50\%) has higher education background while $38.5 \%$ has high school background. Regarding the legal status of respondents $41 \%$ is active white-collar worker, $21.8 \%$ is active blue-collar worker, while $20.5 \%$ was student. Regarding the marital status of respondents $62.8 \%$ is married, $29.5 \%$ is single and $7.7 \%$ is divorced. Regarding the financial situation of respondents $44.9 \%$ has average income.

\section{RESULTS AND DISCUSSION}

With the first question we wanted to reveal how often our respondents eat bread. Figure 2 shows the results.

Figure 2. The frequency of gluten-free bread consumption

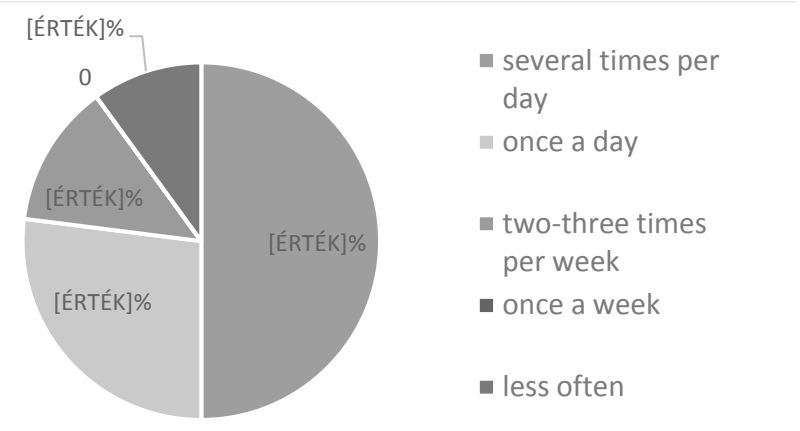

There is a saying that "Hungarians eat bread with bread". Furthermore, leftover bread is often used to thicken soups and stews. As Figure 1 shows bread is essential part of the Hungarian dining habits. It is consumed mostly several times per day. It is rooted in our traditions, habits and traditional meals that are always consumed with bread, such as the traditional Hungarian goulash soup or our great variety of stews. Breakfast is one of the most important main meals in Hungary.

Breakfast is the most important main meal in Hungary. The traditional Hungarian breakfast is based on bread, rolls and crescents. In addition to breakfast, most Hungarian mothers prepare bread, or roll-based sandwiches for their children for elevenses. As Figure 3 shows, breakfast almost cannot be imagined without bread in Hungary.

Figure 3. Frequency of gluten-free bread consumption to main meals

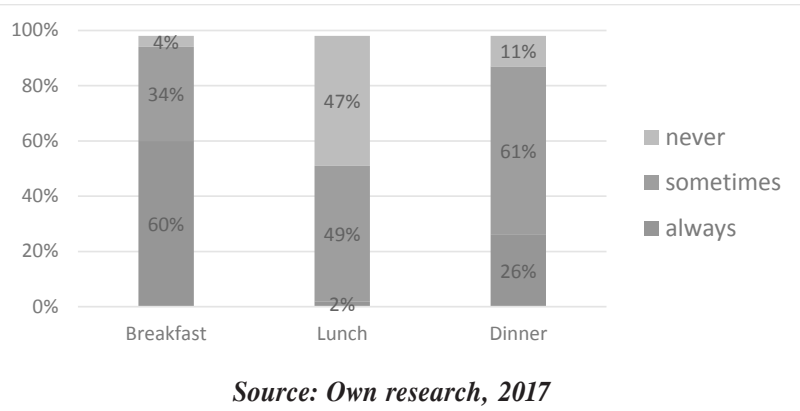

As Figure 2 and 3 shows bread plays an important role in the Hungarian dining habits. Gluten-free breads are different from the conventional ones regarding their characteristics (ingredients, colour, softness, etc.). The availability of these breads are also different, they cannot be purchased so easily like conventional breads. If the buying possibilities of consumers are limited (e.g. they live in villages), it is reasonable for them to buy bread less often but in these cases they buy a bigger amount that is enough for them for a week or even for more. Another possible reason for the low buying frequency (50\%) that respondents may complete the bought bread with self-baked breads. The investigation reveals that $51.3 \%$ of the respondents mainly buys the gluten-free bread. Figure 4 shows the gluten free-bread buying frequencies.

Figure 4. Gluten-free bread buying frequency

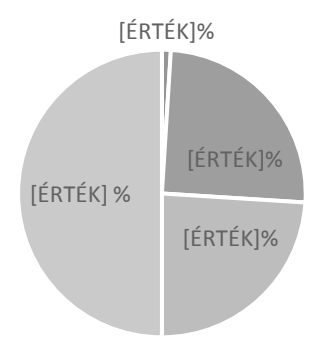

- daily - every two-three days $\quad$ weekly - less often 
Hungarian purchases are generally based on conventional shops including small shops, supermarkets and hypermarkets, as well. The popularity of online shopping is continuously increasing, but so far not as common as the conventional ways of shopping. Figure 5 supports this general fact with the place of purchase of gluten-free beads. Special shops offering foodstuff and dietary supplements for people following special diets are available mainly in bigger towns. As Figure 5 shows respondents prefer these special shops, then supermarkets and multi stores are the most frequent places of purchasing gluten free-bread. In special shops the choice of gluten free breads is rather wide and probably the personal atmosphere and trust are also included in this result. The most obvious reason for buying gluten-free bread in supermarkets and multi stores is that this item is just simply added to the shopping list and it is purchased together with the regularly bought products.

Figure 5. Location of gluten-free bread purchases

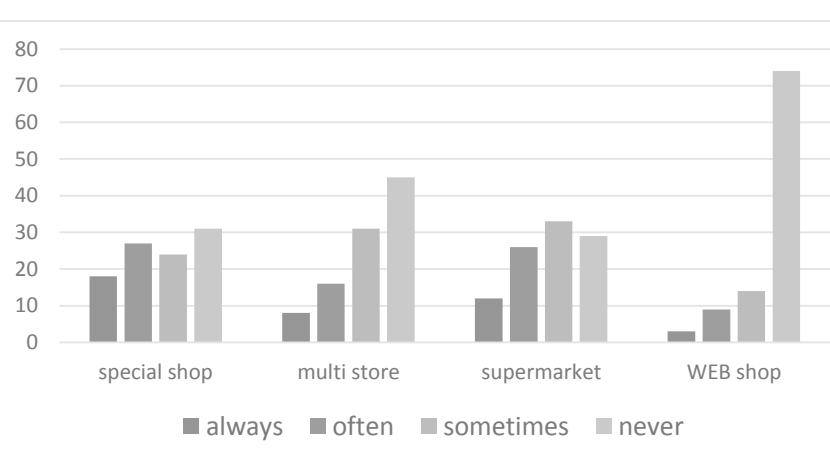

Source: Own research, 2017 (\%)

We asked them if they are loyal to a certain bread brand, if they buy the same bread brand all the time. The research revealed that our respondents are careful. 39.7\% of the respondents said: Yes, mainly; 30.8\% said: Yes, always and only $29.5 \%$ said: No. The most common bread brands (Schär, Mester Család, Nutri Free, Glutenix, Enjoy Free, Spar Free From, Glulu) that are widely available in Hungary were listed and the respondents were requested to mark how often (always, often, sometimes, never) they buy those brands. The investigation revealed that Schär, Enjoy Free and Mester Család are the most popular bread brands as Table 2 shows the results.

Table 2. Preferred bread brands

\begin{tabular}{|l|l|l|}
\hline Which brand do you buy? & always & often \\
\hline Schär (1) & $54 \%$ & $45 \%$ \\
\hline Mester Család (3) & $7 \%$ & $16 \%$ \\
\hline Nutri Free & $0 \%$ & $7 \%$ \\
\hline Glutenix & $3.5 \%$ & $7 \%$ \\
\hline Enjoy Free (Aldi) (2) & $28.5 /$ & $18 \%$ \\
\hline Spar Free From & $3.5 \%$ & $7 \%$ \\
\hline Glulu & $3.5 \%$ & $0 \%$ \\
\hline Total & $100 \%$ & $100 \%$ \\
\hline
\end{tabular}

Source: Own research, 2017
We asked our respondents if they are satisfied with the gluten free bread choice in Hungary. 48.7\% of the respondents said: No; $37.2 \%$ said: Yes, partly and only $14.1 \%$ said: Yes, totally. We also asked them if they are satisfied with the quality of gluten free breads in Hungary. $46.2 \%$ of the respondents said: No; $43.6 \%$ said: Yes, partly; and only $10.2 \%$ said: Yes, totally. Gluten-free products are more expensive than conventional food products, so we wanted to know the opinion of our respondents how satisfied they are with the prices of gluten free breads in Hungary. As a summary, we can state that they consider the prices are rather expensive, as listed below (Expensive: $44.9 \%$ - Unrealistically expensive: $34.6 \%$ - Slightly expensive: $19.2 \%$ - Yes, the price is correct: $1.3 \%)$.

These results (choice, quality, price) can realistically ground the following result, as $74.4 \%$ of the respondents bake bread although the bread baking frequencies are different. We wanted to find out the reasons why they bake bread. The results are as follows: Not satisfied with the quality of the available bread: $23.1 \%$; The price of bread is high: $23.1 \%$; Trust only homemade bread: $11.5 \%$ mentioning the most frequent answers only. We asked our respondents how often they bake bread. $21.8 \%$ of the respondents bakes bread two times a week, $24.4 \%$ once a week, $25.6 \%$ less often, $2.6 \%$ gave other answer. Brand loyalty was a question again. We asked our respondents if they are loyal to a certain brand when buying gluten-free bread flour. The results are as follows: Yes mainly, but try some other brands as well: $57.7 \%$ - Yes, always: $21.8 \%$ - No: $17.9 \%$ - Other answer: $2.6 \%$. Thus, we can state that our respondents are loyal to their ordinary brands. We wanted to find out the out of the listed glutenfree bread flour brands (Anna Panni, Doves Farm, Mester Család, Amisa, Barbara, Bauck Hof, Dia-Welness, Emese, FE-MINI, Glutenix, "Own mixture", Nutri free, Szafi free) which are the most popular ones. Out of these brands Szafi free $(19.2 \%)$ proved to be the most popular one, following by "Own mixture" and Nutri free with $10.3 \%$, respectively, and Mester Család with 9\%.

As can be seen, it is common among the respondents to bake bread. There are several possibilities to bake bread, such as an electric oven, gas oven or bread machine. $47.4 \%$ of the respondents bake bread in an electric oven, $16.7 \%$ in a gas oven, while $11.5 \%$ in a bread machine. The rest does not bake bread or named other options.

As has already been mentioned, the characteristics of gluten-free breads are different comparing them to conventional breads. We wanted to find out how the ideal bread looks like for the respondents. We listed the following characteristics for them: soft, white, brown, grainy, round shape, soft for long time period. They had to mark their opinion on a Likert scale 1-7. Only the most frequent responses are introduced here now:

\begin{tabular}{ll} 
Soft: & $\begin{array}{l}\text { important: } 43.5 \%+\text { very important: } \\
43 \%\end{array}$ \\
\hline White: & not important at all: $27 \%$ \\
\hline Brown: & neutral: $26 \%$ \\
\hline
\end{tabular}




\begin{tabular}{ll}
\hline Grainy: & neutral: $22 \%$ \\
\hline Shape: & not important at all: $24 \%$ \\
\hline $\begin{array}{l}\text { Soft for long } \\
\text { time period: }\end{array}$ & important: $45 \%+$ very important: $35 \%$ \\
\hline
\end{tabular}

Our investigation revealed that softness and softness that is long-lasting are the most important characteristics of the "ideal bread". It should not be white at all and the shape is also not important at all. If it should be brown or grainy, the most frequent answer was: "neutral".

\section{CONCLUSIONS}

Based on our empirical research, we can state:

bread is essential part of the Hungarian dining habits.

Gluten-free bread is consumed mostly several times per day, breakfast almost cannot be imagined without bread in Hungary even in the gluten-free diet,

- $51.3 \%$ of the respondents mainly buys the gluten-free bread,

- $50 \%$ of the respondents less often than weekly buys gluten-free bread, while $24 \%$ buys it on a weekly basis,

- respondents prefer special shops when purchasing gluten free-bread,

- more than $2 / 3$ of the respondents are loyal to a certain brand when buying gluten-free bread,

- among the respondents Schär, Enjoy Free and Mester Család are the most popular bread brands,

- choice and quality of gluten free breads is acceptable, while the price is considered to be high in Hungary,

- $74.4 \%$ of the respondents bake bread although the bread baking frequencies are different

- more than $3 / 4$ of our respondents are loyal to their ordinary brands when buying gluten-free bread flour

- among the respondents Szafi free, "Own mixture", Nutri free and Mester Család are the most popular gluten-free bread flour brands.

It is still a challenge for bakeries to improve the quality of gluten-free breads. The prices of gluten-free foodstuffs are higher than the conventional ones. There is an economic burden for people with celiac disease, since it is not optional for them to choose these special gluten-free foodstuffs. Loyalty to certain brands is strong among the respondents that provides opportunity for producers to develop new products that could be introduced into this special market presumably easier.

During our secondary and primary research, we realized that the consumption habits and lifestyle of people following gluten-free diet is rather complex. Investigation their bread consumption habits proved to be a challenging topic since bread plays important role even in their diet. We realised that this research direction would be worth continuing and widening. Thus, we have drawn up several more prospective and challenging research directions, such as

Reasons for following gluten-free diet. Since not only people with celiac disease follow this diet, family members may also follow the same diet for practical reasons, some people believe this diet as a healthy diet, some people believe they can lose some weight, and it is among the fashion diets, as well.

The gluten-free market is considerably increasing year by year. It is a huge market, even gluten-free dog and cat feeds are available on the market. What are the reasons behind this extraordinary development of the market?

No doubt that it is a costly diet, it would be worth investigating the extra costs of this diet in Hungary comparing traditional menus and gluten-free menus with the same dietary values. Moreover some international comparison would also be interesting.

Subsidisation of celiac people (because of the high costs of the obligatory diet) in international comparison.

Psychological aspects of the gluten-free diet.

Possibilities of people following gluten-free diet in tourism and catering (how this industry can meet their needs, their strict dietary restrictions).

Statistical methods should be applied to show the appropriate differences in figures and trends in all the above mentioned research directions.

\section{REFERENCES}

Arendt E. K., O’Brien C. M., Schober T. J., Gallagher E., Gormley T. R. (2002): Development of gluten-free cereal products, Farm Food 12:21-27.

Ciclitira P. J., Cerio R., Ellis H. J., Maxton D., Nelufer J. M., Macartney J. M. (1985): Evaluation of a gliadin containing gluten free product in celiac patients, Human Nutr. Clin. Nutr. 39:303-308.

Friis S. U. (1996): Celiac disease. Pathogenesis and clinical aspects. PhD thesis. Department of Medical Biochemistry and Genetics. University of Copenhagen: Denmark.

Gallagher E., Gormley T. R., Arendt E. K. (2003): Crust and crumb characteristics of gluten free breads, Journal of Food Engineering 56:153-161.

Gallagher E., Gormley T. R., Arend E.K. (2004): Recent advances in the formulation of gluten-free cereal-based products, Trends in Food Science \& Technology 15 (2004) 143-152. doi: 10.1016/j. tifs.2003.09.012

Gujral H. S., Rosell C. M., Carbonell J. V., Rosell C. M. (2003): Effect of cyclodextrinase on dough rheology and bread quality from rice flour, J. Agric. Food Chem. 51:3814-3818.

Kadan R. S., Robinson M. G., Thibodeaux D. P., Pepperman A. B. (2001): Texture and other physicochemical properties of whole rice bread, Journal of Food Science 66:940-944.

Lowdon J. (2007): Coeliac disease and dietitians - are we getting it right? Journal of Human Nutrition and Dietetics, 2007 Sept; 20, pp. 401-402 doi:10.1111/j.1365-277X.2007.00820.x

McCarthy D. F., Gallagher E., Gormley T. R., Schober T. J., Arendt E. K. (2005): Application of Response Surface Methodology in the Development of Gluten-Free Bread, Cereal Chemistry, Vol. 82, No. 5, 2005: 609-615. doi: 10.1094/CC-82-0609

Nelson M., Mendoza N., McGough N. (2007): A survey of provision of dietetic services for coeliac disease in the UK, Journal of Human Nutrition and Dietetics, 2007, 20, pp. 403-411

Panagiotou S., Kontogianni M.D. (2007): The economic burden of gluten-free products and gluten-free diet: a cost estimation analysis 
in Greece, Journal of Human Nutrition and Dietetics, 2017 May 8. doi: $10.1111 /$ jhn. 12477

Sanchez H. D., Osella C. A., de la Torre M. A. (2002): Optimisation of gluten free bread prepared from corn starch, rice flour and cassava starch, Journal of Food Science 67:416-419.

Sverker A., Östlund G., Hallert C., Hensing G. (2007): Sharing life with a gluten-intolerant person - the perspective of close relatives, Journal of Human Nutrition and Dietetics, 2007 Oct; 20(5):412-422.

Thompson, T. 2001. Wheat starch, gliadin and the gluten free diet. J. Am.

Diet. Assoc. 101:1456-1459.

Thompson, T. 2001. Wheat starch, gliadin and the gluten free diet. J. Am.

Diet. Assoc. 101:1456-1459.

Thompson, T. 2001. Wheat starch, gliadin and the gluten free diet. J. Am.

Diet. Assoc. 101:1456-1459.

Thompson, T. 2001. Wheat starch, gliadin and the gluten free diet. J. Am.

Diet. Assoc. 101:1456-1459.

Thompson, T. 2001. Wheat starch, gliadin and the gluten free diet. J. Am.

Diet. Assoc. 101:1456-1459.

Thompson, T. 2001. Wheat starch, gliadin and the gluten free diet. J. Am.

Diet. Assoc. 101:1456-1459.

Thompson, T. 2001. Wheat starch, gliadin and the gluten free diet. J. Am.

Diet. Assoc. 101:1456-1459
Thompson, T. 2001. Wheat starch, gliadin and the gluten free diet. J. Am.

Diet. Assoc. 101:1456-1459.

Thompson T. (2001): Wheat starch, gliadin and the gluten free diet, J. Am. Diet. Assoc. 101:1456-1459

Ylimaki G., Hawrysh Z. J., Hardin R. T., Thomson A. B. R. (1991): RSM in the development of rice flour yeast breads: Sensory evaluation, Journal of Food Science 56:751-755, 759.

I1: https://www.gluten.org/resources/getting-started/celiac-disease-2/ [accessed Jun 10, 2017].

I2: http://www.drschaer-institute.com/us/professional-articles/aglobal-map-of-celiac-disease-1229.html [accessed Jun 10, 2017].

I3: https:/glutenerzekeny.hu/wp-content/uploads/2015/10/glutenerzenyseg-tajekoztato-kiadvany-201510.pdf [accessed Jun 10, 2017].

I4: https://www.gluten.org/wp-content/uploads/2015/01/EDU_ GFDietFctMyths_.pdf [accessed Jun 10, 2017].

I5: https://www.gluten.org/wp-content/uploads/2015/08/EDU_ WomenGlutenDisorders.pdf [accessed Jun 10, 2017].

I6: http://nfsmi-web01.nfsmi.olemiss.edu/documentlibraryfiles/ PDF/20120327113749.pdf [accessed Jun 12, 2017].

I7: http://www.piackutatasok.hu/2011/11/gfk-friss-pekaruknal-kisboltok.html [accessed Jun 12, 2017].

I8: https://www.gluten.org/wp-content/uploads/2016/11/EDU_Getting-Started-on-a-Gluten-Free-Diet.pdf [accessed Jun 10, 2017]].

I9: http://www.eufic.org/en/healthy-living/article/bread-a-nutritious-staple [accessed Jul 15, 2017].

I10: http://medical-best-help.com/en/pages/688749 [accessed Jul 15, 2017].

I11: http://gluten-free-bread.org/how-to-make-gluten-free-breadflour-mix [accessed Jul 29, 2017]. 
